SSLA, 22, 1-26. Printed in the United States of America.

\title{
TRANSFERABILITY AND PRODUCTIVITY OF L1 RULES IN CATALAN-ENGLISH INTERLANGUAGE
}

\author{
Juli Cebrian
}

University of Toronto

\begin{abstract}
This paper examines the interference of L1 neutralization rules in the acquisition of a marked L2 phonological feature. More specifically, it presents results from a study of the acquisition of the voicing contrast in English word-final obstruents by native speakers of Catalan. The voicing contrast in final position in Catalan is neutralized by voicing or devoicing rules, depending on the environment. The results of an experiment testing the production of target final obstruents in different environments indicate a very high incidence of devoicing, which confirms the prevalence of final devoicing in second language acquisition and points to the joint effect of transfer and universal tendencies. In contrast with devoicing, the results reveal a more limited effect of the L1 voicing rules. It is argued that this difference is due to an effect of word integrity in the interlanguage that restricts the domain of application of the transferred rules.
\end{abstract}

Early work on the acquisition of the phonology of a second language concentrated on the effect of interference from the first or native language (L1). This view was supported by the Contrastive Analysis Hypothesis (Lado, 1957),

\footnotetext{
This paper is based on a study conducted for the author's Master's thesis. Earlier versions of this paper were presented at the EUROSLA conference held in Barcelona, Spain, in May 1997, and, in poster format, at the New Sounds 97 Symposium held in Klagenfurt, Austria, in September 1997. This work was supported in part by a Social Sciences and the Humanities Research Council of Canada (SSHRC) General Research Grant (3-191-390-10) to the author and a SSHRC Research Grant (410-960842) to B. Elan Dresher and K. Rice. Thanks go to Keren Rice and Ron Smyth for their help and encouragement and to the participants in the study both in Toronto and Barcelona.

Address correspondence to Juli Cebrian, Departament de Filologia Anglesa i Germanística, Universitat Autònoma de Barcelona, Facultat de Lletres, Edifici B, Bellaterra 08193, Barcelona, Spain; e-mail: jcebrian@seneca.uab.es.
} 
which predicted the areas of difficulty on the basis of a comparison between the L1 and the second or target language (L2), and explained interlanguage (IL) errors as the result of transfer of structures from the L1. Further research, however, has demonstrated that transfer alone cannot account for all IL errors, and attention has turned to the study of other factors that shape L2 phonology. Eckman (1977) introduced the notion that, in addition to L1 transfer, linguistic universals such as markedness are relevant factors in the formation of an L2 system. Since then, there has been an increasing interest in the interaction between language-specific interference and other IL sources such as typological or markedness universals and developmental processes found in L1 acquisition.

One area of phonology that has drawn considerable attention from L2 researchers and that provides a good ground for the study of transfer and universal processes is the acquisition of syllable-final obstruents and, more specifically, the acquisition of the voicing contrast in final obstruents. The difficulty of acquiring the voicing contrast in final obstruents is predicted by a revised version of the Contrastive Analysis Hypothesis, the Markedness Differential Hypothesis (Eckman, 1977). This hypothesis states that the areas of the L2 that will be difficult are those that are both different from the L1 and relatively more marked. Markedness is defined by the notions of typological markedness and implicational relations. Thus, final voiced obstruents are marked because they are less frequent than their voiceless counterparts cross-linguistically, and because, although the presence of final voiced obstruents in a language implies the presence of final voiceless obstruents, the opposite does not hold.

The acquisition of the English voicing contrast in final obstruents by speakers of Catalan, then, is an example of L2 acquisition of a marked linguistic feature. In acquiring this marked L2 feature, Catalan learners have to overcome their L1 mechanisms for dealing with that marked linguistic feature (i.e., the Catalan rules of regressive voicing and final devoicing). These L1 processes neutralize voicing distinctions in different ways depending on the environment and the type of obstruent. This makes the Catalan-English IL a good language situation for the study of L1 interference. Additionally, this IL situation bears on the issue of the interaction between transfer and universal tendencies, given that the rule of final devoicing is an example of a universal tendency (Eckman, 1977; Yavaş, 1994) found in L1 acquisition (Flege, 1982; Smith, 1979; among others) and prevalent in L2 acquisition, as discussed below. As will be shown, this L2 acquisition process can be further complicated by the existence of an IL restriction on the domain of application of the transferred rules.

\section{RESEARCH IN L2 ACQUISITION OF FINAL VOICED OBSTRUENTS}

The production of L2 final voiced obstruents by L2 learners, and indeed of final obstruents in general, has been the object of study in a number of works 
(Eckman, 1981a, 1981b, 1984, 1987; Edge, 1991; Flege \& Davidian, 1984; Flege, McCutcheon, \& Smith, 1987; Major \& Faudree, 1996; among others). Major and Faudree (1996) confirmed the marked status of the final voicing contrast in a study of the acquisition of English voicing contrast in word-initial, -medial, and -final position by native speakers of Korean, a language with obstruents in all three positions but no phonemic voicing distinction. Korean subjects were more successful at maintaining the voicing contrast initially and medially, with approximately $100 \%$ correct responses, than finally, where the percentage of correct voiced responses was 53\% (the rest were devoiced).

The difficulty in producing voiced obstruents in final position can be explained in aerodynamic terms by the articulatory difficulty of maintaining vocal fold vibration as the supraglottal air pressure increases during the articulation of the final obstruent. Flege et al. (1987) maintained that English speakers learn to enlarge the supraglottal cavity to sustain voicing during the closure. However, adult L2 learners, whose articulatory gestures become fossilized, may be unable to acquire the L2's timely articulatory maneuvers that are necessary in the production of final voiced obstruents.

A number of studies have confirmed this difficulty. Eckman (1981a, 1981b, 1984) elicited English word-final obstruents from speakers of Japanese, Cantonese, Mandarin, Spanish, and Farsi by means of a variety of tasks including repetition, word building, a reading cloze test, and free conversation. He found that Japanese and Mandarin speakers inserted a supporting vowel after the obstruent (schwa paragoge), whereas Cantonese, Spanish, and Farsi speakers showed the effect of final obstruent devoicing (FOD). Eckman concluded that the IL rules could not be explained by transfer because those IL rules were not part of the grammar of any of the L1s. The fact that the rules are not part of the L2 either supported the claim that IL rules are independent from both the L1 and the L2. Additionally, the choice of IL rule was determined by the surface phonetic constraints of the L1. Thus, devoicing was found in the speech of learners whose L1s have final voiceless obstruents but no final voiced obstruents, such as Cantonese, whereas schwa paragoge was more common in the IL of subjects whose L1s have no final obstruents and favor obstruent-vowel sequences, such as Japanese and Mandarin.

Eckman's (1987) claim that IL rules tend to satisfy surface phonetic constraints of the L1 is not supported by the Spanish and Farsi data, however, in which there is no motivation for an IL rule of FOD based on phonetic constraints of the L1. Final stops are rare in Spanish, and the only comparatively common final fricatives are $/ \mathrm{s} /, / \theta /$ (in Iberian dialects), and [ $\delta$ ] (a spirantized allophone of $/ \mathrm{d} /$ ). ${ }^{1}$ Farsi, on the other hand, has both voiced and voiceless obstruents in final position. We would not expect any problem in the production of English final voiced obstruents by Farsi speakers. A similar case is revealed in the IL of Hungarian learners of English. Altenberg and Vago (1983) found that Hungarian speakers devoiced English final obstruents even though Hungarian maintains a voicing contrast in final position. Furthermore, in a study that partially replicated Eckman's (1981b) study, Edge (1991) elicited devoiced 
responses both from Cantonese speakers, for whom they were expected given the surface phonetic constraints of the L1, and from Japanese speakers, for whom they were not predicted. Also, Weinberger (1987) observed that Mandarin subjects, whose L1 has no final obstruents, exhibited devoicing in twothirds of their English word-final obstruents. These studies show that the presence of FOD in an IL cannot always be explained by the characteristics of the L1. In fact, there are even FOD in cases where it is not predicted by the Markedness Differential Hypothesis because the L1 has the same level of markedness as the L2, such as in the speech of Farsi and Hungarian learners of English.

Given the inadequacy of relating IL performance to L1 background alone, further research has turned to other IL sources such as universal tendencies and developmental (L1 acquisition) processes. Flege and Davidian (1984) studied the interaction of L1 interference and developmental processes. They tested the production of English final stops by native speakers of Spanish, Mandarin Chinese, Polish, and English (12 subjects each), elicited by means of a picture-naming task. Mandarin and Spanish speakers showed a few instances of stop deletion, and Spanish speakers showed spirantization. All nonnative speakers exhibited responses involving devoicing. The presence of spirantization in the speech of Spanish subjects, whose L1 has a rule of spirantization, indicates the effect of L1 interference. The occurrences of FOD and final stop deletion illustrate the effect of developmental processes, because both processes are found in L1 acquisition. FOD was the highest source of errors across ILs, which illustrates, once more, the prevalence of this process.

Another factor affecting the production of target obstruents is the phonological environment of the target. In their research on Korean-English IL, Major and Faudree (1996) found some variability in the percentages of correct responses across obstruents. After careful examination of the data, they concluded that this variation had to do with the environment in which the target obstruents were found in a reading passage test-that is, whether the targets were found in sentence-final position or followed by a vowel-initial word. For instance, / $\mathrm{b} /$ was always found sentence finally and elicited a higher number of devoiced responses than $/ \mathrm{g} /$ and $/ \mathrm{d} /$, which were often followed by voiced sounds. The importance of the phonological environment was pointed out by Edge (1991) as well, who found that nonnative speakers were more successful at producing final voiced obstruents when the target preceded a voiced sound or a vowel-initial word. Edge argued that in order to evaluate nonnative speech it is necessary to test the production of target sounds in different environments. It is also necessary to compare the IL data with native L2 data to allow the identification of true nonnative, IL production. For example, she found instances of final devoicing in native English speakers' production before a pause and before a voiceless consonant but rarely before a voiced consonant or a vowel. This finding suggests that the latter are better environments for testing FOD in nonnative speech.

The production of target obstruents may in fact be affected by different 
factors in different environments. In addition to devoicing in final position, Rubach (1984) found that Polish subjects also showed the effect of the L1 rule of voicing assimilation in consonant clusters. In Polish, obstruent clusters, both within words and across word boundaries, must agree in voicing (and devoicing takes place before a pause). The interference of this rule in the subjects' IL was evident in examples such as the pronunciation of $[z]$ instead of [s] in this boy and misgiving. Rubach characterized the types of rules that are likely to transfer as low-level, automatic, context-sensitive rules such as Polish regressive voicing assimilation. Altenberg and Vago (1983) also found evidence of the application of the Hungarian rule of regressive voicing assimilation to L2 English. Like Polish, this rule assimilates an obstruent in voicing to a following obstruent, within a word as well as between words. Some examples of IL errors are the pronunciation of [t] as [d] in about the and [f] as [v] in if the. The presence of regressive voicing in the subjects' IL was interpreted as a case of phonological transfer.

In a study of timing patterns in articulatory gestures, Solé (1997) examined the voicing patterns of Catalan learners of English. Using simultaneous electropalatographic, electroglottographic, and acoustic measurements, Solé tested the production of consonant clusters whose members differ in voicing (such as [sn] in snail) by two native English speakers and four Catalan learners of English. The Catalan subjects differed from the English subjects in that they showed one single glottal gesture for two segments in their production of both English and Catalan words. This anticipatory voicing gesture was not found in the native English speakers. Solé concluded that articulatory habits concerning the synchronization of different gestures, such as those governing anticipatory voicing or FOD alluded to above, are carried over to the L2. Examples of this anticipatory voicing pattern are the pronunciation of $[\mathrm{z}]$ in this book and in smile (with an epenthetic vowel, e.g., [əzmajl]), and [d] in place of /t/ in sit down.

The marked status of final voiced obstruents in L2 acquisition is amply supported by the empirical evidence summarized in this section. FOD emerges as a very productive IL rule, regardless of its presence or absence in the L1. Regressive voicing also affects IL production in speakers whose L1 has a rule of voicing assimilation. The current study examines the production of the marked final voicing contrast by speakers of a language that neutralizes this contrast by means of voicing and devoicing rules, depending on the environment. Let us first review the facts about the L1 patterns.

\section{THE L1 RULES}

Catalan has a number of obstruents that contrast in voicing word initially and medially, but the contrast is neutralized word finally due to FOD and voicing rules. Examples are given in Tables 1, 2, and 3. In absolute final position, that is, before a pause, obstruents are always voiceless, as illustrated in Table 1, which also provides examples of word-medial intervocalic contrast. 
Table 1. Neutralization in prepausal position (final obstruent devoicing)

\begin{tabular}{|c|c|c|c|c|}
\hline \multirow[b]{2}{*}{ Obstruent } & \multicolumn{2}{|r|}{ Word finally } & \multicolumn{2}{|c|}{ Intervocalically } \\
\hline & FOD & Gloss & Contrast & Gloss \\
\hline \multicolumn{5}{|c|}{ Continuants } \\
\hline /z/ & $v a[s]$ & "glass" & $v a[z] o s$ & "glasses" \\
\hline$/ \mathrm{s} /$ & go $[s]$ & "dog" & go $[s] o s$ & "dogs" \\
\hline \multicolumn{5}{|l|}{ Stops } \\
\hline /b/ & $r e[p]$ & "he (or she) receives" & $r e[b] r e^{a}$ & "to receive" \\
\hline$/ \mathrm{p} /$ & $e s c u[p]$ & "he (or she) spits" & esco[p]ir & "to spit" \\
\hline
\end{tabular}

${ }^{a}$ Voiced stops in this position in fact surface as spirants (e.g., re[ $\left.\beta\right]$ re). FOD = final obstruent devoicing.

Table 2. Final obstruents in consonant clusters

\begin{tabular}{|c|c|c|c|c|}
\hline \multirow[b]{2}{*}{ Obstruent } & \multicolumn{2}{|r|}{$\mathrm{C}_{\text {[+voice] }}$} & \multicolumn{2}{|r|}{$\mathrm{C}_{\text {[-voice] }}$} \\
\hline & RVA & Gloss & FOD & Gloss \\
\hline \multicolumn{5}{|c|}{ Continuants } \\
\hline |z/ & $v a[z]$ gran & "big glass" & va[s] petit & "small glass" \\
\hline$/ \mathrm{s} /$ & go $[z]$ gran & "big dog" & go[s] petit & "small dog" \\
\hline \multicolumn{5}{|l|}{ Stops } \\
\hline$/ \mathrm{b} /$ & re $[b]$ molts & $\begin{array}{l}\text { "he (or she) receives } \\
\text { lots" }\end{array}$ & re $[p]$ cartes & $\begin{array}{l}\text { "he (or she) receives } \\
\text { letters" }\end{array}$ \\
\hline$/ \mathrm{p} /$ & escu[b] molt & $\begin{array}{l}\text { "he (or she) spits a } \\
\text { lot" }\end{array}$ & $e s c u[p]$ tot & $\begin{array}{l}\text { "he (or she) spits } \\
\text { everything" }\end{array}$ \\
\hline
\end{tabular}

Note. $\mathrm{RVA}=$ regressive voicing assimilation; $\mathrm{FOD}=$ final obstruent devoicing.

Table 3. Final obstruents preceding a vowel-initial word

\begin{tabular}{llll}
\hline Process & Obstruent & & Gloss \\
\hline RVA & Continuants & & \\
& $/ \mathrm{z} /$ & va $[z]$ ample & "large glass" \\
& $/ \mathrm{s} /$ & go $[z]$ astut & "cunning dog" \\
FOD & Stops & re $[p]$ això & "receive this" \\
& $/ \mathrm{b} /$ & escu[p] això & "spit this" \\
\hline
\end{tabular}

Note. $\mathrm{RVA}=$ regressive voicing assimilation; FOD = final obstruent devoicing.

In consonant clusters, regressive voicing assimilation (RVA) affects obstruents preceding a consonant within the same phrase, that is, not followed by a pause. Obstruents take on the voicing of a following voiced consonant or are neutralized to voiceless preceding a voiceless consonant, as shown in Table $2 .{ }^{2}$ Another RVA rule voices fricatives and affricates, but not stops, when followed by a vowel-initial word in the same phrase, as illustrated in Table 3. 
Word-final stops are still affected by FOD when followed by a vowel-initial word (Mascaró, 1983; Recasens, 1993; among others). ${ }^{3}$

FOD applies equally to all voiced obstruents. The labiodental fricative (/f/) and the affricate $(/ \mathrm{t} / /)$, however, display a certain degree of variability with respect to RVA that is related to frequency effects and dialectal differences. Recasens (1993) noted that the labiodental fricative, which is relatively uncommon in coda position, does not undergo regressive voicing as regularly as more common final fricatives such the alveolar $(/ \mathrm{s} /)$ and the palato-alveolar $(/ \mathrm{S} /$ ). In his view, voicing is more common when $/ \mathrm{f} /$ is far from the main stress. Mascaró (1983), on the other hand, in a less phonetically based analysis, stated that all fricatives and affricates are equally affected by RVA, including nonnative sounds like the interdental fricative found in foreign words. With respect to dialectal traits, in some varieties of Eastern Catalan, speakers fail to voice final affricates $(/ \mathrm{t} /$ / in prevocalic position, and some speakers even devoice affricates word internally (Recasens, 1993, 1996). As discussed in the Experimental section, in the current study, the subjects' performance in Catalan was also tested by means of a reading passage. Thus, in addition to examining the interference of the L1 processes, the study of final obstruents in this IL could also investigate the effect of RVA on sounds that are foreign, uncommon, or subject to variation in the L1. For the sake of brevity, this paper focuses mainly on the results concerning the transferability of RVA and discusses only briefly the variation found among continuants, which was found to parallel L1 patterns.

\section{PREDICTIONS}

As I have shown, research on the acquisition of final voiced obstruents points to the prevalence of final devoicing, a rule that is found in many ILs regardless of the characteristics of the L1 and even when the L1, in fact, has final voiced obstruents. This prevalence of FOD has been explained by a number of factors. It is a developmental process found in L1 acquisition and even, to a certain extent, in adult speech in English (Edge, 1991; Flege, 1982). Furthermore, given its presence in the grammar of many natural languages (e.g., Russian, German, Polish, Dutch, and Catalan) and its phonetic motivation, it is an example of a typologically unmarked universal tendency (Eckman, 1991; Ellis, 1994; Yavaş, 1994).

On the other hand, evidence from Polish, Hungarian, and Catalan speakers indicates that voicing assimilation rules are also likely to affect the acquisition of a voicing contrast in final position. In fact, the Catalan rules of RVA fit the description of transferable rules. According to several studies, the kinds of L1 rules that cause interference are low level, exceptionless, sensitive to context, and applicable across the board in the L1 (Altenberg \& Vago, 1983; Hammarberg, 1990; James, 1988; Rubach, 1984). In articulatory terms, this transferability derives from the difficulty in changing the fossilized articulatory timing habits that govern anticipatory voicing in the L1 (Solé, 1997). 
Juli Cebrian

Table 4. Voicing in coda obstruents in Catalan and English

\begin{tabular}{llc}
\hline Environment & $\begin{array}{c}\text { Catalan (L1) } \\
\text { neutralization } \\
\text { (process) }\end{array}$ & $\begin{array}{c}\text { English (L2) } \\
\text { contrast }\end{array}$ \\
\hline \# (pause) & voiceless (FOD) & voiced and voiceless \\
$-\mathrm{C}_{\text {[-voice] }}$ & voiceless (FOD) & voiced and voiceless \\
\#V & voiceless (FOD) & voiced and voiceless \\
stops & voiced (RVA) & voiced and voiceless \\
nonstops & voiced (RVA) & voiced and voiceless \\
C $_{\text {[+voice] }}$ & voiced \\
\hline $\begin{array}{l}\text { Note. RVA = regressive voicing assimilation; FOD }=\text { final obstruent de- } \\
\text { voicing. }\end{array}$ &
\end{tabular}

Difficulty in acquiring target final voiced obstruents is predicted by the marked status of the final voicing contrast. The L1 rules are expected to interfere with the production of target obstruents because the same input and the same environment for the L1 rules are found in the L2, thus meeting the structural overlap between the L1 and the L2 necessary for transfer to take place (Rubach, 1984). The prediction is, then, that the production of final obstruents by Catalan learners will vary from one environment to another according to which rule governs the neutralization in each environment in the L1. The predicted interference of the L1 rules is based on the unmarked universal nature of FOD and the low-level, exceptionless nature of the assimilation rules. The environments and the neutralization processes of the L1 are summarized in Table 4, which includes a comparison with the L2 contrast.

\section{THE EXPERIMENT}

An experiment was designed to test Catalan native speakers' production of English word-final obstruents in the four relevant environments shown in Table 4 (before a pause, preceding a heterosyllabic voiceless consonant, preceding a heterosyllabic voiced consonant, and before a vowel-initial word). It was important to test the production of obstruents in these four different environments for two major reasons. First, by taking the environment into account, we were able to control for true cases of nonnative production because, as discussed in the section on previous L2 research, some environments are more indicative of actual IL processes than others (Edge, 1991). Second, although coda obstruents are always neutralized in the L1, the result of the neutralization process depends on the environment and the type of obstruent.

\section{Subjects}

The subjects were 12 native Catalan speakers, adult learners of English as an L2 (2 males and 10 females). The subjects' ages ranged from 17 to 39 years, 
Table 5. Examples of test items

\begin{tabular}{|c|c|c|c|c|}
\hline \multirow[b]{2}{*}{ Phoneme } & \multicolumn{4}{|c|}{ Four environments } \\
\hline & -\# & $\mathrm{C}_{\text {[-voice] }}$ & $-\mathrm{C}_{[+ \text {voice }]}$ & _\#V \\
\hline /b/ & pub & pub crawl & pub night & pub owner \\
\hline /d/ & proud & proud son & proud girl & proud artist \\
\hline $\mid \mathrm{z} /$ & wise & wise person & wise guy & wise advice \\
\hline$|\theta|$ & south & south side & south border & south east \\
\hline
\end{tabular}

with a mean age of 24. All subjects were native speakers of Eastern Catalan varieties spoken in and around Barcelona, Spain. ${ }^{4}$ Given the dialectal differences across native speakers of Catalan, the subjects' performance in Catalan was measured in a reading passage test. All subjects were found to devoice where expected and to voice in voicing environments, although some variation was found with the affricate, as will be discussed below. The group included four subjects with an undergraduate degree in English, six current ESL students (in Barcelona), and two learners who were temporarily residing in Toronto. The level of proficiency of the subjects was determined by their performance during a conversation in English with the experimenter. Three native English speakers listened to the conversations and rated the subjects on the basis of their grammar and pronunciation. The four English majors and one of the residents of Toronto obtained similar and comparatively higher scores than the other seven subjects, whose scores were also fairly close. Proficiency, however, was not found to play any role in the results, at least with respect to the production of L2 word-final obstruents, as discussed below.

\section{Targets and Tasks}

The target items in the experiment were English words ending in one of the eight English obstruent voiceless-voiced pairs (/p-b/, /t-d/, /k-g/, /f-v/, / $\theta-\mathrm{d} /$, $/ \mathrm{s}-\mathrm{z} /, / \mathrm{f}-3 /, / \mathrm{t}-\mathrm{d} / 3 /)$, presented in the four relevant contexts. For every environment, five examples of each obstruent were elicited. For example, there were five items ending in $/ \mathrm{p} /$ for each of the environments, totaling 20 items containing a word-final $/ \mathrm{p} /$, plus 20 more ending in the voiced counterpart $(/ \mathrm{b} /)$, and so on. ${ }^{5}$ The total number of tokens elicited per subject was 292. Examples of final obstruents in the four environments are given in Table 5.

The experiment consisted of four main tasks plus a control text in Catalan and the brief conversation in English used for rating proficiency. The Catalan control text was a short story that included a number of word-final obstruents in order to test the subjects' performance with respect to voicing and devoicing rules in their native language and to estimate the variability among continuant obstruents discussed above. The subjects were unaware of the purpose of the Catalan text.

The bulk of the experiment consisted of four main tasks designed to elicit 
Table 6. Examples of translation task and definition task

\begin{tabular}{|c|c|c|c|}
\hline \multicolumn{2}{|c|}{ Translation task } & \multicolumn{2}{|l|}{ Definition task } \\
\hline $\begin{array}{l}\text { Stimulus } \\
\text { (Catalan } \\
\text { word) }\end{array}$ & $\begin{array}{c}\text { Response } \\
\text { (English } \\
\text { translation) }\end{array}$ & Stimulus (definition) & Response \\
\hline pont & bridge & Another word for taxi & $c a b$ \\
\hline ou & egg & The color of snow & white \\
\hline moure & move & $\begin{array}{l}\text { Flower that a Catalan woman gets } \\
\text { on St. Jordi's Day }\end{array}$ & rose \\
\hline
\end{tabular}

Table 7. Example of word-grouping (WG) task

\begin{tabular}{|c|c|c|c|}
\hline \multicolumn{3}{|c|}{ Stimulus (oral) } & \multirow{2}{*}{$\frac{\text { Response }}{\text { Word } 1+\text { Word } 3}$} \\
\hline Word 1 & Word 2 & Word 3 & \\
\hline $\begin{array}{l}\text { deaf } \\
\text { south }\end{array}$ & $\begin{array}{l}\text { shine } \\
\text { brick }\end{array}$ & $\begin{array}{l}\text { neighbor } \\
\text { east }\end{array}$ & $\begin{array}{l}\text { deaf neighbor } \\
\text { south east }\end{array}$ \\
\hline
\end{tabular}

Table 8. Example of word-building (WB) task

\begin{tabular}{ll}
\hline Stimulus (oral) & Response \\
\hline $\begin{array}{l}\text { member of a club } \\
\text { ice which is smooth }\end{array}$ & $\begin{array}{l}\text { club member } \\
\text { smooth ice }\end{array}$ \\
\hline
\end{tabular}

obstruents in the relevant environments while at the same time trying to avoid orthographic interference. Items for the FOD environments were elicited mainly by means of a translation task and a definition task. These tasks are illustrated in Table 6. In the translation task, subjects had to translate a list of Catalan words into English; in the definitions task, subjects had to say the word that best matched a given definition.

Pairs of words for RVA environments were mostly elicited in two tasks referred to as the Word Grouping task and the Word Building task. These are shown in Tables 7 and 8. In the Word Grouping (WG) task, subjects heard a series of three words and had to repeat the first and third words, which resulted in a well-formed sequence or phrase. In the Word Building (WB) task, subjects were asked to repeat the definition they heard in just two words by switching the order of the words in the definition from a postmodified noun to a compound or a premodified noun.

The stimuli used for the WG and WB tasks were recorded by a female native Canadian English speaker. The materials were pretested on another native Catalan speaker, as well as on a native English speaker. The native English data made it possible to compare the Catalan subjects' performance to a native speaker's. 


\section{Data Analysis}

The responses were transcribed separately by the experimenter, who is a native Catalan speaker, and by a second transcriber, who is a native Canadian English speaker with experience in transcription. The two transcriptions were then compared and cases of disagreement were either resolved by the two transcribers or otherwise eliminated from the analysis. Because the goal of the experiment was to test the acquisition of the voicing contrast, the data analysis concentrated on the presence or absence of voicing in the targets. In fact, the vast majority of errors involved voicing or devoicing-that is, voiced targets rendered as voiceless or voiceless targets produced as voiced. The predominance of (de)voicing errors is discussed in the Results and Discussion sections. The very few responses involving deletion or epenthesis were eliminated. The empty cells resulting from discarded responses were filled with the average for that cell. In any case, empty cells amounted to less than $2 \%$ of the total data.

Although based on perceptual data, without additional acoustic analysis, I believe the scoring method is reliable because judging voicing on the basis of perception is representative of the way sounds are heard in everyday speech situations and mispronunciations due to nonnative voicing patterns contribute considerably to the perception of accented speech. In a study involving Chinese speakers of English as a second language, Flege et al. (1987) found that the lack of perceptually effective contrast between $/ \mathrm{p} /$ and $/ \mathrm{b} /$ was correlated with an instrumentally analyzed lack of a closure duration difference, and often voicing difference, between $/ \mathrm{p} /$ and $/ \mathrm{b} /$. Furthermore, basing this study on a perceptual analysis makes it comparable to other studies such as Flege and Davidian (1984), Edge (1991), and Major and Faudree (1996).

Additionally, the analysis of the data obtained from the native English speaker demonstrated that targetlike production was detectable given that there was no difficulty with differentiating voiced and voiceless obstruents in native speech. The detectability of voicing in native speech is due to a number of phonetic and acoustic characteristics that cue obstruent voicing in final position. One of these cues is the duration of the preceding vowel, which is longer before a voiced obstruent than before a voiceless one (Peterson \& Lehiste, 1960, among others). ${ }^{6}$

The transcribers' subjective impression was that the performance of nonnative speakers lacked a systematic effect of such temporal cues. Although vowel duration was not measured acoustically, the reported lack of vowel duration effect is consistent with other L2 studies (e.g., Flege \& Davidian, 1984; Flege \& Port, 1981) and with phonetically based studies that demonstrate that nondiscrete physical or phonetic characteristics of the L1 are hard to overcome and those of the L2 are very difficult to acquire (Mitleb, 1984; Solé, 1997). For instance, in Flege and Port's (1981) study of the acquisition of the English stop voicing contrast by Saudi Arabian Arabic speakers, whose L1 does not have vowel duration as a cue to voicing, it was found that, even after 
Table 9. Mean scores for final obstruent devoicing across tasks and subjects

\begin{tabular}{cccc}
\hline & Before a pause & & Before $\mathrm{C}_{[- \text {voice] }}$ \\
\cline { 2 - 2 } Obstruent & Devoiced responses & & Devoiced responses \\
\hline /b/ & $99 \%$ & & $87 \%$ \\
$/ \mathrm{d} /$ & $94 \%$ & $92 \%$ \\
$/ \mathrm{g} /$ & $98 \%$ & $95 \%$ \\
$/ \mathrm{v} /$ & $98 \%$ & $100 \%$ \\
$/ \mathrm{d} /$ & $100 \%$ & $100 \%$ \\
$/ \mathrm{z} /$ & $98 \%$ & & $100 \%$ \\
$/ 3 /$ & $96 \%$ & $100 \%$ \\
$/ \mathrm{d} /$ & $100 \%$ & & $100 \%$ \\
Mean & $97.8 \%$ & & $96.8 \%$ \\
\hline
\end{tabular}

several years in an English-speaking environment, the Saudi learners' production of English final stops exhibited the same small and nonsignificant vowel duration differences as L1 Arabic. On the other hand, as Flege and Davidian (1984) pointed out, it cannot be concluded that failure to produce final voicing is solely the result of the absence of the vowel-duration cue, because vowel duration is not the only cue to final obstruent voicing in English (see Flege \& Davidian, 1984, for more discussion on this issue).

The responses involving final devoicing and regressive voicing were computed and analyses of variance (ANOVAs) were performed on the means per subject for each of the four dependent measures-namely, absolute final devoicing, preconsonantal devoicing, preconsonantal voicing, and prevocalic voicing. The variables were Task (two different tasks were used for each environment), Voice (the underlying voicing status of the English targets, i.e., voiced or voiceless), and Sound (the eight English obstruent pairs, collapsing over voicing, i.e., /p-b/, /t-d/, /k-g/, /f-v/, / $\left.\theta-\delta /, / s-z /, / \int-3 /, / t-d z /\right)$. Voice was a variable for RVA environments but not for FOD environments because devoicing can be tested on voiced targets only.

The overall results of the experiment supported the prediction that the L1 rules are transferred, but there was a clear difference in productivity between them.

\section{RESULTS}

\section{Preceding a Pause and Preceding a Voiceless Obstruent}

The predicted productivity of FOD in these environments was strongly supported by the results. Subjects had great difficulty in producing final voiced obstruents, as illustrated in Table 9, which presents the mean devoicing scores per target voiced obstruent in final position before a pause or before a voiceless consonant. Voiceless obstruents, on the other hand, were produced 
with $100 \%$ accuracy. Notice that interpreting the voiceless responses as the result of devoicing presupposes that subjects have the correct, targetlike underlying representation of final voiced obstruents. This assumption is substantiated by evidence from morphophonemic alternations. For example, although subjects failed to distinguish safe from save, they produced the correct voicing when the obstruent was medial, as in safer or saving. ${ }^{7}$

The $2 \times 8$ (Task $\times$ Sound) within-subjects ANOVA showed no significant main effects and no interaction for the absolute final condition. In preconsonantal position, the two-way ANOVA detected a significant effect of Sound, $F(7,77)=4.19, p<.001$, explained by the fact that stops obtained lower devoicing rates than continuants ( $87-95 \%$ vs. $100 \%$, respectively) but no effect of Task. The significance of the different patterning of stops and continuants was confirmed by a planned comparison test, $F(1,11)=7.59, p<.05$.

This difference between stops and continuants, in fact, resembles the pattern usually found in English adult speech and in L1 acquisition, which shows that devoicing is more likely with fricatives than with stops. ${ }^{8}$ Nevertheless, this result is not paralleled in other L2 studies in which no significant effect of obstruent type has been found (Edge, 1991; Major \& Faudree, 1996). Further, whereas an analogy to L1 phenomena may explain the effect of obstruent type in preconsonantal position, it fails to capture the absence of a similar effect in prepausal position. Another potential explanation involves the perceptual nature of the scoring and the difference in articulatory and acoustic properties between the two sound types. Fricatives are longer and involve friction instead of total closure, whereas stops are short and were often unreleased. Consequently, the voicelessness of a coda fricative in a cluster was more clearly perceived than in the case of a coda stop, which may have resulted in the smaller number of acceptable targetlike responses with nonstops than with stops. This Sound effect was also found with preconsonantal voicing, discussed below.

\section{Preceding a Voiced Consonant}

In order to test the interference of the L1 voicing rules, the production of both voiced and voiceless obstruents was analyzed and the number of voiced responses was computed. The variability of the results obtained for this context contrasts with the uniformity found before a pause and before a voiceless consonant. Subjects deviated from the L2 in that they displayed a number of voiced responses for voiceless targets (negative transfer of voicing assimilation) and of voiceless responses for voiced targets (devoicing). However, the results also differ from the systematic neutralization characteristic of the L1. Table 10 gives the mean percentages of targetlike, devoiced, and wrongly voiced responses for the eight voiced and voiceless targets, collapsed across tasks and subjects.

The three-way (Task $\times$ Voice $\times$ Sound) within-subjects ANOVA yielded a significant main effect of Voice, $F(1,11)=13.83, p<.01$, and Sound, $F(7,77)=$ 
Table 10. Percentages of voiced and voiceless responses before a voiced consonant

\begin{tabular}{|c|c|c|c|c|c|}
\hline \multicolumn{3}{|c|}{ Voiced targets } & \multicolumn{3}{|c|}{ Voiceless targets } \\
\hline \multirow[b]{2}{*}{ Obstruent } & \multicolumn{2}{|c|}{ Responses } & \multirow[b]{2}{*}{ Obstruent } & \multicolumn{2}{|c|}{ Responses } \\
\hline & Voiced $^{\mathrm{a}}$ & Devoiced & & Voiceless & Voiced $^{\mathrm{b}}$ \\
\hline /b/ & 59 & 41 & $/ \mathrm{p} /$ & 64 & 36 \\
\hline /d/ & 68 & 32 & $/ \mathrm{t} /$ & 68 & 32 \\
\hline /g/ & 53 & 47 & $/ \mathrm{k} /$ & 56 & 44 \\
\hline$/ \mathrm{v} /$ & 27 & 73 & $/ \mathrm{f} /$ & 93 & 7 \\
\hline /ð/ & 18 & 82 & $\mid \theta /$ & 92 & 8 \\
\hline$|\mathrm{z}|$ & 25 & 75 & $/ \mathbf{s} /$ & 78 & 22 \\
\hline$|3|$ & 25 & 75 & $\mid \mathrm{s} /$ & 92 & 8 \\
\hline$/ d_{3} /$ & 13 & 87 & $/ \mathrm{tg} /$ & 97 & 3 \\
\hline Mean & 36 & 64 & Mean & 80 & 20 \\
\hline
\end{tabular}

${ }^{\mathrm{a}}$ Positive transfer of regressive voice assimilation. ${ }^{\mathrm{b}}$ Negative transfer of regressive voice assimilation.

$12.19, p<.001$. The analysis also revealed a significant Task-Sound interaction, $F(7,77)=2.63, p<.05$, and a marginal Voice-Sound interaction, $F(7,77)=2.06$, $p<.06$. The main effect of Voice results from the fact that more voiced responses were obtained for voiced targets than for voiceless targets across subjects and sound types. This finding indicates that the IL makes a distinction that is not found in the L1.

The main effect of Sound is seen, first, in the overall difference between the two obstruent types. Stops elicited a significantly higher number of voiced responses than nonstops, evidencing a higher percentage of both positive and negative transfer. This significance was confirmed in a follow-up planned comparison test, $F(1,11)=33.52, p<.001$. As seen above, when discussing preconsonantal devoicing, this difference between stops and continuants may be related to their different phonetic properties and the result of evaluating voicing on the basis of speech perception. Additionally, the effect of Sound results from the variability found within obstruent type, as evidenced by the different results among continuants, and from the higher incidence of voicing responses yielded by the alveolar fricative. This within-group variability, which mainly reflects L1 patterns, was also found in prevocalic condition, as discussed below.

Finally, the isolated case of an interaction involving Task can be explained by the failure of the labial stops and the alveolar fricatives in the WG task to duplicate the overall pattern of significantly lower voicing scores for the fricatives than for the stops. This failure is probably due to the uneven distribution of items involving voiced and voiceless labial stops and alveolar fricatives between the two tasks (WB and WG) and to the related main effect of Voice. On the other hand, the marginal interaction between Voice and Sound resulted from the unique pattern of the alveolar fricative, the only sound to dis- 
Table 11. Percentages of voiced and voiceless responses before a vowel

\begin{tabular}{|c|c|c|c|c|c|}
\hline \multicolumn{3}{|c|}{ Voiced targets } & \multicolumn{3}{|c|}{ Voiceless targets } \\
\hline \multirow[b]{2}{*}{ Obstruent } & \multicolumn{2}{|c|}{ Responses } & \multirow[b]{2}{*}{ Obstruent } & \multicolumn{2}{|c|}{ Reponses } \\
\hline & Voiced & Devoiced & & Voiceless & Voiced \\
\hline \multicolumn{6}{|l|}{ Stops } \\
\hline$/ \mathrm{b} /$ & 8 & 92 & $/ \mathrm{p} /$ & 100 & 0 \\
\hline$/ \mathrm{d} /$ & 38 & 62 & $/ \mathrm{t} /$ & 94 & 6 \\
\hline /g/ & 19 & 81 & $/ \mathrm{k} /$ & 100 & 0 \\
\hline Mean & 22 & 78 & Mean & 98 & 2 \\
\hline \multicolumn{6}{|l|}{ Nonstops } \\
\hline$/ \mathrm{v} /$ & $38^{\mathrm{a}}$ & 62 & /f/ & 84 & $16^{\mathrm{b}}$ \\
\hline /ర/ & $31^{\mathrm{a}}$ & 69 & $\mid \theta /$ & 80 & $20^{\mathrm{b}}$ \\
\hline $\mid \mathrm{z} /$ & $56^{\mathrm{a}}$ & 44 & $/ \mathrm{s} /$ & 58 & $42^{\mathrm{b}}$ \\
\hline$|3|$ & $42^{\mathrm{a}}$ & 58 & $/ \mathrm{s} /$ & 78 & $22^{\mathrm{b}}$ \\
\hline$/ d_{3} /$ & $28^{\mathrm{a}}$ & 72 & $/ \mathrm{t} J /$ & 92 & $8^{\mathrm{b}}$ \\
\hline Mean & 39 & 61 & Mean & 78 & 22 \\
\hline
\end{tabular}

play a fairly equal number of RVA responses for both the voiced and the voiceless targets (i.e., a similar amount of positive and negative transfer).

\section{Prevocalic Position}

In prevocalic position, the L1 neutralization pattern varies according to obstruent type: Stops are voiceless, whereas continuant obstruents are voiced. Table 11 gives the mean percentages of correct, devoiced, and wrongly voiced responses for the eight voiced and voiceless targets, collapsed across tasks and subjects.

The analysis of RVA responses in prevocalic position also evidenced a main effect of Voice, $F(1,11)=11.61, p<.01$, and Sound, $F(7,77)=7.67, p<$ .001 , but no interaction. As in the preconsonantal voicing condition, the effect of Voice results from the fact that voiced targets yielded a higher number of voiced responses than voiceless targets. The main effect of Sound is due, first, to the smaller number of voicing responses with stops than with nonstops. A follow-up planned comparison test proved significant, $F(1,11)=12.11, p<.01$. In this case, the effect of obstruent type is an example of L1 interference because continuant obstruents, but not stops, show the effect of the L1 rule of prevocalic voicing. The $6 \%$ voiced responses found with the voiceless coronal stop, as well as the higher number of voiced responses for /d/ among voiced stops, may arise from the influence of the L2 rule of intervocalic flapping.

The effect of Sound also results from the different percentages of voicing responses elicited by different sounds and from the higher incidence of voicing responses yielded by the alveolar fricative, both in the voiceless and the 
voiced condition. As with preconsonantal voicing, the variability of voicing responses contrasts with the regularity found with FOD. This variability reflects the L1 patterns alluded to earlier (see Cebrian, 1996, for a more detailed discussion of this Sound effect). The L1 patterns were corroborated by the subjects' performance in the Catalan control text. ${ }^{9}$ Across environments, the most common word-final L1 fricative, the alveolar $(/ \mathrm{s}-\mathrm{z} /)$, was the sound that yielded the highest percentage of voicing, followed by the palato-alveolar $\left(/ \int-3 /\right)$ and the labiodental (/f-v/). The lowest percentage of voicing was elicited by the affricate $\left(/ \mathrm{t} f-\mathrm{d}_{3} /\right) .{ }^{10}$ In fact, the alveolar was the sound that followed the L1 neutralization pattern more closely because it obtained similar scores for both the voiceless and the voiced target. The interdental fricative is not a native Catalan phoneme. Not surprisingly, it patterned more like /f/, a rare wordfinal fricative, than like /s/, which is common in word-final position. The relatively high scores for the voiced labiodental target (/v/) may be related to the fact that $[\mathrm{v}]$ is not a distinctive Catalan phoneme but just an allophone of $/ \mathrm{f} /$. Thus, together with the effect of the L1 voicing process that affected all sounds, there may have been an additional factor accounting for the voiced responses for $/ \mathrm{v} /$-namely, the conscious and independent effort to produce a new target sound.

\section{DISCUSSION}

The overall results of the experiment supported the prediction that the L1 rules are transferred, as illustrated by the high rates of devoicing and the different patterning of stops and nonstops in prevocalic position. There was, however, a clear difference in the extent of transferability between FOD and the RVA rules. On the other hand, level of proficiency was not found to be a factor, because all subjects exhibited similar percentages of devoicing and voicing, which stresses the difficulty and marked status of final voiced obstruents. This finding is consistent with the account given by Flege and Davidian (1984), who found no significant correlation between the acquisition of final voicing and age of arrival. The effect of the environment, the prevalence of FOD, and the extent of positive and negative transfer of the voicing rules are discussed next.

\section{The Effect of the Environment}

As illustrated in Table 12, subjects were more successful at producing final voiced obstruents before a voiced consonant and before a vowel than preceding a voiceless consonant or a pause. For example, of the three environments in which final voiced stops cannot be the result of L1 interference, prevocalic position yielded the highest number of voiced responses (a mean of $22 \%$ ), notably higher than before a voiceless consonant or a pause $(9 \%$ and $3 \%$, respectively). Additionally, the amount of voicing with nonstops is significantly greater in prevocalic position (39\%) than in preconsonantal position $(22 \%)$. 
Table 12. Percentages of correct responses by environment and obstruent type

\begin{tabular}{lrccc}
\hline Obstruents & $\ldots \#$ & $-\mathrm{C}_{\text {[-voice] }}$ & $-\mathrm{C}_{\text {[+voice] }}$ & $-\# \mathrm{~V}$ \\
\hline Voiced targets & & & & \\
$\quad$ Stops & 3 & 9 & 60 & 22 \\
$\quad$ Nonstops & 2 & 0 & 22 & 39 \\
Voiceless targets & & & & \\
$\quad$ Stops & 100 & 100 & 63 & 98 \\
$\quad$ Nonstops & 100 & 100 & 90 & 78 \\
\hline
\end{tabular}

The correlation in percentages of voicing across the two contexts was highly significant, $R^{2}=.86, F(1,9)=43.2, p<.001$.

This finding is consistent with the trend found in other L2 studies, as mentioned above. Major and Faudree (1996) attributed the fact that a higher number of correct final voiced stops were elicited in a reading text $(63 \%)$ than in a word list (38\%) to the possibility of coda consonants in a text linking with onsetless vowels in the following syllable. The higher incidence of voicing in prevocalic position could thus be a result of resyllabification (also an example of L1 interference), as in the syllabification of size eight as [saj ze't] or move out as [mu vawt]. The resyllabified obstruent is no longer in coda position but in onset position, intervocalically, where voicing is no longer marked. This position also makes voicing more perceptible. Additionally, an obstruent preceding a vowel or a voiced consonant resides between two voiced phonemes, a position that facilitates voicing.

\section{Prevalence of FOD}

The high productivity of final devoicing is evident in the high devoicing rates obtained before a pause and before a voiceless consonant, as shown in Table 9. Subjects also devoiced preceding a voiced consonant or a vowel, stressing the truly nonnative (i.e., non-English) nature of FOD. These results indicate extremely high scores of FOD responses compared to results from other L2 studies. For instance, Major and Faudree (1996) reported 47\% devoicing in the responses of their Korean subjects, and the percentages obtained by Flege and Davidian (1984) were 48.3\% for Polish, 29.5\% for Mandarin Chinese, and 43\% for Spanish speakers.

A possible explanation for the high number of FOD responses in the present study could be found in the nature of the tasks, which were designed to avoid orthographic interference and to conceal the purpose of the experiment. Major and Faudree (1996), on the other hand, used a reading passage and a word list-that is, tasks that allow for orthographic interference. Although Flege and Davidian (1984) elicited targets with a picture-naming task, their test items consisted of five minimal pairs and the goal of the test might have been more transparent to the subjects. 
Additionally, Cebrian (1997) tested the production of final voiced obstruents (and other phonological variables) by Catalan learners of English in six different tasks that differed with respect to the amount of self-monitoring they allowed, and obtained higher percentages of correct voiced responses than the current study. His results also corroborated the difficulty of suppressing the L1 devoicing rule because tasks allowing for little self-monitoring and no orthographic interference resulted in low percentages of voiced responses. However, even tasks that drew the speakers' attention to their own speech, like a minimal-pairs reading list, yielded less than $50 \%$ targetlike responses. This is consistent with the results of Hammarberg's (1990) study of the acquisition of Swedish final voiced obstruents by native speakers of German. Hammarberg found that devoicing dropped from $91 \%$ in free conversation to $58 \%$ in an imitation test.

The devoicing scores in Hammarberg (1990), Cebrian (1997), and the current study are still comparatively high, even in the more favorable tasks. Thus, another reason for the predominance of FOD responses may reside in the fact that, in these studies, the unmarked rule of FOD is part of the L1s (German and Catalan). The issue of the interaction of transfer and universal tendencies is discussed in more detail in the last section of this paper.

\section{Interference of L1 Voicing Rules}

The results for the voicing environments show that the voicing rules are indeed transferred into the speakers' IL, as evidenced by the voiced responses to voiceless targets before a voiced consonant (20\%) and before a vowel for nonstops (22\%), as shown in Tables 10 and 11. This contrasts with the 100\% correct voiceless responses before a pause or a voiceless consonant. These results are consistent with the findings of Rubach (1984) and Altenberg and Vago (1983), and follow from the difficulty in overcoming L1 articulatory timing patterns on the part of adult learners of a foreign language. The influence of the L1 is also evident in the variability found among obstruents. First, the different results for stops and continuants in prevocalic position are the direct result of the fact that the L1 rule of prevocalic voicing targets fricatives and affricates only. Second, the variability of responses among fricatives and affricates, and the higher voicing rates for the alveolar fricative, mirror L1 patterns, as discussed above.

An interesting consequence of the interference of $\mathrm{L} 1$ patterns in the IL is the fact that, as a result of the positive transfer from the L1, targetlike pronunciation may be fortuitously produced. The same target voiced obstruent may be voiced in an L1 voicing environment but voiceless in an L1 devoicing environment. For example, learners may accidentally produce a voiced alveolar fricative in nosebleed but fail to do so when saying the word nose in isolation. This factor was also described in the Cebrian (1996) study, with respect to the production of the voiced interdental fricative. Catalan learners produced voiced interdental fricatives in environments that matched the L1 rule of spi- 
rantization but failed to produce them in other environments. Major (1994) provided similar examples involving Spanish learners and spirantization. This fact underlines the need to examine sounds in different contexts when estimating the degree of acquisition of an L2.

However, subjects did not simply follow L1 patterns, which would have rendered a higher and equal number of voiced responses for both voiced and voiceless targets. The incidence of positive transfer is stronger than that of negative transfer. This result may indicate that subjects are aware of the L2 voicing contrast to some extent: They are somewhat more successful at suppressing the voicing rule when its application results in deviation from the target sound than when it renders a targetlike sound. This is particularly evident with underlyingly voiceless continuants in preconsonantal position (excluding $/ \mathrm{s} /$ ), which are affected by voicing in less than $10 \%$ of the cases. Further, as Tables 10 and 11 show, voiced targets were still devoiced in 61$64 \%$ of the cases in voicing environments. Therefore, whereas the interference from the L1 is robustly supported by the productivity of FOD in the IL, it is only marginal with respect to the rules of RVA. It is proposed in this paper that the difference in productivity between the voicing and devoicing rules may in part stem from an IL word-integrity effect that restricts the domain of application of the transferred L1 processes, as discussed next.

\section{An IL Prosodic Constraint}

The low productivity of the voicing rules may derive from the prosodic characteristics of the test items. The current study tested the effect of RVA mostly across word boundaries, as in Swiss girl, south border, smooth ice, or fresh apples. The difference in productivity between the L1 rules of FOD and RVA can be accounted for by the existence of an effect of word integrity in the IL that treats every word as a separate unit and prevents the articulatory synchronization of sounds belonging to different words. This effect can be represented as an IL prosodic constraint that restricts the application of rules to the level of the phonological word. One way of implementing this constraint was pausing between the two words, which eliminated the word-contact environment. ${ }^{11}$

This effect of word integrity can be illustrated with examples from the experiment. The target final obstruent in word pairs such as Swiss girl or smooth ice fails to undergo the L1 rule of RVA because each word in the pair constitutes a phonological word (i.e., $\{\text { Swiss }\}_{\mathrm{w}}\{\text { girl }\}_{\mathrm{w}}$ ) and the IL constraint blocks the application of RVA across a word boundary $\left({ }^{*}\{\operatorname{Swi}[\mathrm{z}]\}_{\mathrm{w}}\{\operatorname{girl}\}_{\mathrm{w}}\right)$. Additionally, a final voiced obstruent in a word sequence, as in smooth ice, is affected by FOD (e.g., $\{\operatorname{smoo}[\theta]\}_{\mathrm{w}}\{\text { ice }\}_{\mathrm{w}}$ ), given that the IL constraint prevents the positive transfer of the voicing rule and makes this environment equivalent to one in which the obstruent precedes a voiceless consonant or a pause. Thus, the L1 rules are transferred, but, whereas the existence of this IL constraint does not affect the application of FOD, which is already manifest within the phono- 
logical word, it prevents RVA from applying more regularly because it was tested mainly across a word boundary.

The postulation of such an IL effect of word integrity finds no parallel in other L2 studies, such as those discussed above, which report a stronger influence of the L1 voicing rules. Nevertheless, in those studies, the obstruent affected by voicing was either word internal-for example, /s/ pronounced [z] in misgiving (Rubach, 1984) and in smile (pronounced [əzmajl], Solé, 1997) - or word final in a sequence containing a prosodically weak word-for example, [z] in this boy (Rubach), this is (Altenberg \& Vago, 1983), and this book, and [d] for /t/ in sit down (Solé). Noncontent words, such as clitics and grammatical words, do not count as words in prosodic phonology but are considered to associate with a host or content word to form part of a phonological word (Nespor \& Vogel, 1986). Thus, in those cases, voicing took place within phonological words, not across phonological words.

Additional evidence for the effect of word integrity can be found in cases of RVA affecting word-internal clusters and in cases of word-final obstruents in prosodically weak forms. RVA was tested mainly across a word boundary (e.g., Swiss girl), but a few word-internal clusters were elicited in compounds like blackboard or iceberg. Such clusters yielded a larger number of voiced responses. This finding seems to indicate that a word like blackboard is interpreted as a single word (\{blackboard $\}_{\mathrm{w}}$ ) rather than two different word units and regressive voicing of the velar stop is not blocked by the IL constraint (bla[g]board).

Furthermore, Cebrian (1996) found that word-final obstruents were indeed affected by the voicing rules when they occurred in a sequence of a prosodically weak form and a strong form, which could be analyzed as constituting one phonological word unit. An illustration of this is the phrase bag of apples. In this case, the prevocalic labiodental fricative in coda position $(o[v])$ is rendered as voiced. ${ }^{12}$ If the preposition and the following noun are assumed to form a phonological word, the final obstruent is no longer at the edge of the phonological word and undergoes regressive voicing ( $\{o[v]$ apples $\})$.

Cebrian (1996) found evidence from spirantization that word sequences that include prosodically weak forms pattern like single phonological words. Spirantization in Catalan affects onset voiced stops preceded by a continuant sound. ${ }^{13}$ This too is a low-level exceptionless rule that causes interference, as exemplified by the IL pronunciation of $[\chi]$ instead of /d/ in reading. Spirantization was also found with word-final voiced stops in sequences containing pronouns and prepositions, such as the pronunciation of $/ \mathrm{d} /$ as [ठ] in read it. Recall that target voiced stops preceding a vowel-initial word tended to be devoiced, following L1 devoicing patterns, not spirantized. The presence of a voiced spirant in sequences like read it can be explained as the result of treating the verb-pronoun sequence as a single word, with the target voiced stop occupying an onset.

Further research involving a wider range of data and L1s would be necessary to assess the effect of such a constraint in more ILs. It is also necessary 
to examine more compounds of the blackboard type and sequences involving weak forms, as well as test the extent of anticipatory voicing in word sequences produced in running speech, where not as much attention is given to individual words as in the present tasks. Nevertheless, the results point to the proposed prosodic domain as a factor that can block otherwise transferable L1 processes. This accounts for the difference in productivity between the two transferred rules.

\section{IL STRATEGIES AND UNIVERSAL TENDENCIES}

The high rates of FOD produced by Catalan learners of English point to the joint effect of L1 interference and universal or markedness tendencies. On the one hand, the productivity of FOD is the result of the transfer of the L1 rule of devoicing into the IL, and of the fact that devoicing escapes the IL prosodic constraint that limits the application of the voicing rules. On the other hand, the high incidence of FOD is related to its unmarked, universal nature (Eckman, 1991; Yavaş, 1994) and phonetic motivation, as discussed above. Its universal character is further supported by cases of speakers who show final devoicing in the L2 even though their native language has final voiced obstruents and no FOD, as seen with Farsi and Hungarian learners of English. For all these reasons, Chambers (1995) characterized FOD as a primitive process, one that is very difficult to suppress when found in the speaker's L1. Therefore, the high productivity of FOD in this IL may result from the combined effect of its presence in the L1, its universal nature, and the difficulty of suppressing it.

Hammarberg's (1990) study of the acquisition of Swedish final voiced obstruents by native speakers of German, a language with a rule of final devoicing, also obtained high devoicing rates, ranging from $58 \%$ to $91 \%$, depending on the task. The proposed joint effect of L1 interference and universal tendencies predicts that speakers of languages like Catalan, who have a native rule of FOD, will exhibit a higher percentage of devoiced responses than speakers of languages with no devoicing rule.

The effect of having a native rule of devoicing was one of the issues examined by Flege and Davidian (1984). They compared the performance of speakers of Spanish and Mandarin, with no native rule of devoicing, with that of Polish speakers, whose L1 has FOD. The prediction that Polish speakers would yield higher rates of devoicing, however, was not borne out. Although Polish speakers did exhibit more devoiced responses than the other groups, the difference between language groups did not reach significance (48.3\% for Polish, 29.5\% for Mandarin, and 43\% for Spanish). Nevertheless, the authors reported a wide range of individual variation within each language group that may have obscured possible between-group differences. The Polish subjects were also said to produce final stops that seemed to be phonetically intermediate to the voiced and voiceless stop categories produced by the native 
Table 13. Strategies used by the Spanish subject

\begin{tabular}{lrll}
\hline Strategy & $\%$ & Example & Gloss \\
\hline Final devoicing & 7 & $c r a[p]$ & "crab" \\
Lenition & 7 & {$\left[w a j^{d}\right]$} & "wide" \\
Deletion & 14 & {$[d r a]$} & "drug" \\
Paragogic vowel & 29 & $b a\left[g^{\circ}\right]$ & "bag" \\
Correct responses & 43 & $j o[b]$ & "job" \\
\hline
\end{tabular}

English subjects, so that the exact amount of devoicing in this IL may not have been evident.

In order to help assess the effect of having an unmarked process in the L1, the current experiment was run on a native Spanish speaker. Recall that final obstruents are infrequent in Spanish and that they tend to undergo lenition processes like spirantization or deletion rather than FOD. The Spanish subject's production of final voiced stops evidenced a variety of L2 strategies, as illustrated by the means presented in Table 13 .

Although a more thorough analysis of the Spanish-English IL with a larger sample of subjects is necessary in order to properly compare the results from Spanish speakers with the results from Catalan speakers, the preliminary test reported here evidences that the two groups pattern quite differently. The variety of responses listed in Table 13 clearly diverges from the Catalan speakers' pattern involving only very high percentages of FOD. These results can be compared to results available from other studies involving Spanish speakers mentioned above. For instance, Eckman (1981b, 1987) showed that FOD was one of several strategies used by Spanish learners, and the percentage of FOD obtained in that study was $36 \%$.

The variety of responses found with Spanish subjects contrasts not only with the results for Catalan speakers but also with those of the Polish speakers in the Flege and Davidian (1984) study. Although Flege and Davidian did not find a significant difference in the amount of FOD responses observed in different language groups, they did find that Polish subjects, like Catalan subjects, displayed mainly FOD responses (48\% vs. only $1.2 \%$ spirantization and $0 \%$ deletion), whereas Spanish subjects exhibited deletion (3.4\%) and spirantization (19.3\%) as well. Furthermore, in his study of German learners of Swedish, Hammarberg (1990) stated that substitution errors almost invariably involved devoiced responses. Therefore, comparing the performance of Catalan, Polish, and German learners to that of speakers of other languages strongly suggests an effect of a universal tendency in the L1, manifest not simply in the comparatively higher percentages of devoicing, which could be due to the nature of the tasks or the scoring methods, but more notably in the fact that FOD is the main or predominant source of errors. Notice that this predominance is explained by both its presence in the L1 and its universal character. Its unmarked universal nature alone cannot account for the results because, if that were the case, FOD would be predominant in all ILs, regard- 
less of language background. Similarly, its strength cannot be explained solely as L1 interference because nonuniversal L1 rules like Spanish spirantization are not found to transfer to the same extent.

More research comparing different ILs may be necessary to clarify the relation between interference from the L1 and language universals, but the current results indicate that the joint effect of L1 interference and universal tendencies adds to the productivity of an L1 rule and to the difficulty of suppressing it in the IL. In other words, when the L1 rules fall within the category of unmarked tendencies, transfer is the predominant L2 strategy.

\section{CONCLUSION}

This study has examined the production of English final voiced obstruents by speakers of an L1 that neutralizes the voicing contrast in final position by means of context-sensitive voicing and devoicing processes. The experiment stresses the importance of the environment in testing L2 speech, and confirms the conclusions of previous research that subjects produce a higher number of correct voiced responses before a voiced consonant and before a vowelinitial word. The study of this particular IL provides further evidence for the marked nature of final voiced obstruents and the unmarked nature of FOD. L1 interference is evident in the differing patterns of the two obstruent types in prevocalic position and in the variability found among continuants. Although both voicing and devoicing processes are found to cause interference, the results reveal a considerable difference in the extent to which each rule was transferred. The lower productivity of the voicing rules can be explained by the effect of the integrity of the word in the IL, which restricts the application of such rules across phonological words. The very high incidence of FOD and, more important, the predominance of FOD responses in this IL, as opposed to the variety of strategies found in other ILs, is interpreted as a joint effect of transfer and universal or developmental processes; when the L1 rules can be characterized as unmarked tendencies, transfer is the predominant source of L2 errors.

(Received 1 October 1998)

\section{NOTES}

1. Studies that involve Spanish as an L1 have not interpreted devoicing as a possible L1 rule (e.g., Eckman 1981b; Flege \& Davidian, 1984). Tomás Navarro (1963) stated that, in the few instances in which voiced stops are found in final position, they tend to be affected by lenition or spirantization processes rather than by devoicing. The Spanish rule of spirantization is indeed found to cause interference in L2 acquisition (Eckman, 1987; Flege \& Davidian, 1984).

2. Notice that, contrary to what happens in other languages with RVA, such as Dutch, voicing in Catalan is triggered not only by voiced obstruents but also by sonorants (e.g., re [b] molts "he (or she) receives lots'). Thus, preconsonantal RVA was tested with both sonorants and voiced obstruents as triggers.

3. Devoicing and voicing rules affect obstruents in coda position only (both word-final and word-internal codas); there is no voicing assimilation within onset clusters. Although the term coda 
devoicing may be more accurate, I will refer to the devoicing process as final obstruent devoicing to be consistent with the terminology used in the literature.

4. These speakers are in fact bilingual Spanish-Catalan speakers. However, they constitute a different population from monolingual Spanish speakers. This is evident in the fact that the Spanish spoken by native Catalan speakers commonly exhibits the effect of the Catalan devoicing and prevocalic voicing rules not found in the speech of Spanish monolinguals.

5. There were the same number of items for each environment and each sound, with the exception of $/ \delta /$ and $/ 3 /$, which had fewer tokens due to the limited number of English words ending in these two sounds (at least words that an ESL learner would know).

6 . Vowel duration is not found to be a cue to final voicing in Catalan. Dinnsen and Charles-Luce (1984) claimed to have found a significant effect of vowel duration in an experiment on phonetic implementation of Catalan word-final obstruents. However, their result is based on the performance of only one subject out of five who yielded significantly shorter vowels in the environment _C \# C when the final stop was voiceless. Furthermore, as argued in Mascaró's (1987) reply to Dinnsen and Charles-Luce's paper, there are a number of problems with the latter's experiment, including the wrong choice of underlying representation for test words. In a reanalysis of the data, Dinnsen and Charles-Luce (1987) found no significant effect of preceding vowel duration, although they reported that a small difference in voicing into consonant closure proved significant.

7. I did not test the underlying status of all final obstruents in the experiment. However, the assumption that learners have targetlike underlying representations is also supported by further observations from this and other studies (Cebrian, 1996, 1997) that Catalan learners do not devoice final obstruents in medial position-for example, the / $\mathrm{v}$ / in living room-although they devoice them finally (live). Additionally, the learners' knowledge of English orthography is also likely to influence their L2 underlying representations.

8. Edge (1991) reported a small percentage of devoicing in native English speakers that affected mostly fricatives and rarely stops. This is in agreement with Ohala's (1983) finding that fricatives are more than twice as likely to be voiceless as are stops, and with results from L1 acquisition showing that voiced stops are usually acquired before voiced fricatives and affricates (Major \& Faudree, 1996).

9. The Catalan text readings showed that RVA varied across subjects and sounds. With respect to the variation across sounds, the alveolar fricative (/s-z/) was voiced on practically all occasions $(99 \%)$, followed closely by the palato-alveolar $\left(/ \int-3 /\right)$. The affricate $(/ \mathrm{t} f-\mathrm{d} 3 /)$ failed to voice in almost $40 \%$ of the cases and the labiodental (/f-v/) yielded the lowest voicing scores (33\%). These results lend support to Recasens' (1993) view on the irregular pattern of the labiodental and the affricate. Subjects differed mainly in the degree of voicing they exhibited with the labiodental fricative and the palato-alveolar affricate.

10. An anonymous reviewer indicated that some Eastern Catalan speakers tend to devoice the affricate even in intervocalic position word-medially. This could explain the lower percentages of voicing found with the affricate. Thus, I examined whether the extent of IL voicing that each individual exhibited with the affricate reflected the degree of prevocalic voicing of the same sound in the Catalan reading passage. Those subjects who voiced the affricate more often in the Catalan text did not necessarily exhibit more voicing responses in English. Thus, as a whole, variability across sounds mirrored native patterns, but individually there was no relation between the amount of voicing in the L1 and in the IL.

11. Voiceless responses under this pausing condition were still recorded as nonvoicing responses and thus added to the number of responses that did not involve RVA. It could be argued that these responses should not be considered as a lack of voicing because, as a result of pausing, the environment for RVA is removed. Nevertheless, I decided to count them as nonvoicing responses for several reasons. First, the two transcribers could not reach sufficient agreement with respect to the presence or absence of pauses (interestingly enough, the Catalan native speaker detected pauses more often than the English native speaker). Additionally, a statistical analysis demonstrated that, although removing the pausing responses from the analysis resulted in overall higher percentages of voiced responses, the difference between these and the percentages including pausing responses did not reach significance. Excluding the pausing responses yielded the same significant effects of Sound and Voice, with higher voicing responses for voiced targets and for the alveolar over other obstruents. Even though pausing accounts in part for the low productivity of the voicing processes in the IL, the high number of voiceless responses that did not involve pausing still supports the proposed IL prosodic constraint. Rather than being the cause of the constraint, pausing was most likely a result of it.

12. I am assuming that the final labiodental in of is underlyingly voiceless in the learners' IL, most 
likely due to orthographic interference. In any case, even if it were correctly assumed to be voiced, it would neutralize to voiceless in coda position.

13. Unlike in other Iberian languages, spirantization in Catalan affects voiced stops only in onset position, not in coda position, where they are subject to devoicing and voicing (Mascaró, 1984; Palmada, 1994). Given the syllabic restriction in Catalan, it is not surprising that spirantization of final voiced stops was not exhibited by Catalan learners, although it is found in Spanish-English IL (Eckman, 1981b; Flege \& Davidian, 1984).

\section{REFERENCES}

Altenberg, E., \& Vago, R. (1983). Theoretical implications of an error analysis of second language phonology production. Language Learning, 33, 427-448.

Cebrian, J. (1996). Voicing in final obstruents and the transfer of phonological rules in Catalan-English interlanguage. Unpublished Master's thesis, University of Toronto, Ontario, Canada.

Cebrian, J. (1997). Stylistic variation in Catalan-English interlanguage. In L. Rowsell, C. Burns, \& L. Blair (Eds.), Proceedings of the 1997 Meeting of the Canadian Linguistics Association (pp. 13-24). Calgary, Canada: University of Calgary.

Chambers, J. K. (1995). Sociolinguistic theory: Linguistic variation and its social significance. Oxford: Blackwell.

Dinnsen, D. A., \& Charles-Luce, J. (1984). Phonological neutralization, phonetic implementation, and individual differences. Journal of Phonetics, 12, 49-60.

Dinnsen, D. A., \& Charles-Luce, J. (1987). A reanalysis of Catalan devoicing. Journal of Phonetics, 15, $187-190$.

Eckman, F. R. (1977). Markedness and the contrastive analysis hypothesis. Language Learning, 27, 315-330.

Eckman, F. R. (1981a). On predicting difficulty in second language acquisition. Studies in Second Language Acquisition, 4, 18-30.

Eckman, F. R. (1981b). On the naturalness of interlanguage phonological rules. Language Learning, 31, $195-216$.

Eckman, F. R. (1984). Universals, typologies, and interlanguage. In W. Rutherford (Ed.), Language universals and second language acquisition: Vol. 5. Typological studies in language. Amsterdam: Benjamins.

Eckman, F. R. (1987). On the naturalness of interlanguage phonological rules. In G. Ioup \& S. H. Weinberger (Eds.), Interlanguage phonology: The acquisition of a second language sound system (pp. 125-144). Cambridge: Newbury House.

Eckman, F. R. (1991). The structural conformity hypothesis and the acquisition of consonant clusters in the interlanguage of ESL learners. Studies in Second Language Acquisition, 13, 23-41.

Edge, B. A. (1991). The production of word-final obstruents in English by L1 speakers of Japanese and Cantonese. Studies in Second Language Acquisition, 13, 377-393.

Ellis, R. (1994). The study of second language acquisition. Oxford: Oxford University Press.

Flege, J. E. (1982). English speakers learn to suppress stop devoicing. In K. Tuite, R. Schneider, \& R. Chametzky (Eds.), Papers from the 18th Regional Meeting of the Chicago Linguistic Society (pp. 111-122). Chicago: Chicago Linguistic Society.

Flege, J. E., \& Davidian, R. D. (1984). Transfer and developmental processes in adult foreign language speech production. Applied Psycholinguistics, 5, 323-347.

Flege, J. E., McCutcheon, M. J., \& Smith, S. C. (1987). The development of skill in producing wordfinal English stops. Journal of the Acoustical Society of America, 82, 433-447.

Flege, J. E., \& Port, R. (1981). Cross-language phonetic interference: Arabic to English. Language and Speech, 24, 125-146.

Hammarberg, B. (1990). Conditions on transfer in phonology. In A. R. James \& J. Leather (Eds.), New sounds 90: Proceedings of the 1990 Symposium on the Acquisition of Second-Language Speech (pp. 198-215). Dordrecht: Foris.

James, A. R. (1988). The acquisition of a second language phonology: A linguistic theory of developing sound structures. Tübingen: Gunter Narr.

Lado R. (1957). Linguistics across cultures. Ann Arbor: University of Michigan Press.

Major, R. C. (1994). Current trends in interlanguage phonology. In M. Yavaş (Ed.), First and second language phonology (pp. 181-204). San Diego, CA: Singular.

Major, R. C., \& Faudree, M. C. (1996). Markedness universals and the acquisition of voicing contrasts by Korean speakers of English. Studies in Second Language Acquisition, 18, 69-90. 
Mascaró, J. (1983). La fonologia catalana i el cicle fonològic. Barcelona: Universitat Autònoma de Barcelona.

Mascaró, J. (1984). Continuant spreading in Basque, Catalan, and Spanish. In M. Aronoff and R. T. Oehrle (Eds.), Studies in phonology presented to Morris Halle by his teacher and students (pp. 287298). Cambridge, MA: MIT Press.

Mascaró, J. (1987). Underlying voicing recoverability of finally devoiced obstruents in Catalan. Journal of Phonetics, $15,183-186$

Mitleb, F. M. (1984). Voicing effect on vowel duration is not an absolute universal. Journal of Phonetics, $12,23-27$.

Nespor, M., \& Vogel, I. (1986). Prosodic phonology. Dordrecht: Foris.

Ohala, J. J. (1983). The origin of sound patterns in vocal tract constraints. In P. F. MacNeilage (Ed.), The production of speech (pp. 189-216). New York: Springer-Verlag.

Palmada, B. (1994). La fonologia del català: Els principis generals i la variació. Barcelona: Universitat Autònoma de Barcelona.

Peterson, G., \& Lehiste, I. (1960). Duration of syllabic nuclei in English. Journal of the Acoustical Society of America, 25, 175-184.

Recasens, D. (1993). Fonètica i fonologia. Barcelona: Enciclopèdia Catalana.

Recasens, D. (1996). Fonètica descriptiva del català (assaig de caracterització de la pronúncia del vocalisme $i$ consonantisme del català al segle XX). Barcelona: I.E.C. Biblioteca Filològica XXI.

Rubach, J. (1984). Rule typology and phonological interference. In S. Eliasson (Ed.), Theoretical issues in contrastive phonology: Studies in descriptive linguistics (pp. 37-50). Heidelberg: Julius Groos.

Smith, B. L. (1979). A phonetic analysis of consonantal devoicing in children's speech. Journal of Child Language, 6, 19-28.

Solé, M. J. (1997). Timing patterns in the production of a foreign language. In L. Díaz \& C. Pérez (Eds.), Views on the acquisition and use of a second language: Proceedings of the European Second Language Association 7th Annual Conference (pp. 539-551). Barcelona: Universitat Pompeu Fabra.

Tomás Navarro, T. (1963). Manual de pronunciación española. New York: Hafner.

Weinberger, S. H. (1987). The influence of linguistic context on syllable simplification. In G. Ioup \& $\mathrm{S}$. H. Weinberger (Eds.), Interlanguage phonology: The acquisition of a second language sound system (pp. 401-417). Rowley, MA: Newbury House.

Yavaş, M. (1994). Final stop devoicing in interlanguage. In M. Yavass (Ed.), First and second language phonology (pp. 267-282). San Diego, CA: Singular. 